\title{
LABSOCIAL - DROGAS: UMA EXPERIÊNCIA DIALÓGICA POR MEIO DA EXTENSÃO CURRICULAR NO CURSO DE DIREITO DA UFT
}

RVD

Recebido em

13.02.2020

Aprovado em

27.05 .2020

\section{LABSOCIAL - DRUGS: A DIALOGUE EXPERIENCE THROUGH CURRICULAR EXTENSION IN THE UFT COURSE OF LAW}

\author{
Gabriel Alves da Costa Neto 1 \\ Gustavo Ferreira Amaral ${ }^{2}$ \\ Matheus Morais Lemos ${ }^{3}$ \\ Milena Gabriela Rodrigues Barros ${ }^{4}$ \\ Patrício Reis Ferreira ${ }^{5}$ \\ Cristiane Roque de Almeida ${ }^{67}$
}

\begin{abstract}
RESUMO
Por meio deste trabalho, relatamos a experiência de criação coletiva do projeto de extensão LabSocial - Drogas: experiências dialógicas entre a universidade e a sociedade, no contexto do programa de extensão Centro Regional de Referência sobre Drogas - CRR/UFT/CENTROSUL, do Curso de Direito da Universidade Federal do Tocantins - UFT. Destacamos os resultados das primeiras ações do projeto, realizadas durante o ano de 2019 na Escola Estadual Elizângela Glória Cardoso, em Palmas-TO, com jovens do Ensino Médio. A atividade extensionista demonstrou que o laboratório de ideias, na perspectiva do trabalho horizontal e interdisciplinar, é uma estratégia valiosa à abordagem da "questão social das drogas", devendo ser considerada no trabalho com jovens no ambiente escolar, bem como em outros espaços formativos.
\end{abstract}

\footnotetext{
1 Discente do curso de Direito da Universidade Federal do Tocantins (UFT). E-mail: gabrielneto88@hotmail.com

2 Discente do curso de Direito da Universidade Federal do Tocantins (UFT). E-mail: amaral.gustavo@mail.uft.edu.br

3 Discente do curso de Direito da Universidade Federal do Tocantins (UFT). E-mail: matheuslemosgpi17@gmail.com

4 Discente do curso de Direito da Universidade Federal do Tocantins (UFT). E-mail: milenagrbarros@gmail.com

5 Discente do curso de Direito da Universidade Federal do Tocantins (UFT). E-mail: patricio.ferreira@mail.edu.br

${ }^{6}$ Doutoranda pela Rede Bionorte/UFT. Mestre em Sociologia. Docente no Curso de Direito da UFT e orientadora do trabalho. E-mail: crisroque@uft.edu.br ORCID https://orcid.org/0000-0003-2149-3855

${ }^{7}$ Curso de Direito - Câmpus Universitário de Palmas Quadra 109 Norte, Avenida NS 15, Bloco BALA II, Sala 15. Cep: 77001-090 / Palmas-TO
} 
https://doi.org/10.20873/uft.2359-0106.2020.v7n2.p449-461

PALAVRAS-CHAVE: Diálogo horizontal. Drogas e juventudes. Filosofia pop. Laboratório de ideias. Prevenção ao uso indevido de drogas.

\begin{abstract}
Through this work, we report on the collective creation experience of the extension Project LabSocial - Drugs: A dialogue experience through between university and society, in the context of the Regional Drug Reference Center extension program - CRR/UFT/CENTRO-SUL, of the law course at the Federal University of Tocantins - UFT. We highlight the results of the first actions of the project, conducted in 2019 in the school Escola Estadual Elizângela Glória Cardoso, in Palmas-TO, with high school young people. The extension activity demonstrated that the idea laboratory, from the perspective of horizontal and interdisciplinary work, is a valuable strategy to approach of the "social issue of drugs", should be considered with young people in the school environment, as well as in other formative spaces.
\end{abstract}

Keywords: Horizontal dialogue. Drugs and youths. Pop philosophy. Idea labs. Drug abuse prevention.

\title{
1 INTRODUÇÃO
}

No Estado do Tocantins, a partir do ano de 2015, foi implementado o Centro Regional de Referência sobre Drogas - CRR/UFT/Centro-Sul, incentivado pela Secretaria Nacional de Políticas sobre Drogas do Ministério da Justiça - SENAD/MJ, para articular ações formativas voltadas ao cuidado em caso de uso indevido de substâncias. (ALMEIDA, 2017). O CRR é um programa de extensão vinculado ao Curso de Direito da UFT, e o LabSocial - Drogas: experiências dialógicas entre a universidade e a sociedade um projeto de extensão, a ele vinculado, para capacitar estudantes universitários para o planejamento e a promoção de intervenções sociais interdisciplinares sobre drogas. É um laboratório de ideias, um espaço de diálogo que visa discutir, em perspectiva horizontal, a "questão social das drogas".

A proposta do LabSocial - Drogas é de ser um espaço formativo dialógico, a partir das experiências e dos objetivos dos envolvidos - tanto docentes, técnicos, quanto acadêmicos e público externo - refletindo acerca de um novo sentido de vida. Esse diálogo se faz necessário pois a questão das drogas vem sendo debatida e pesquisada há muito tempo em diversas sociedades, com diversos pontos de partida e metodologias, e no Brasil, a abordagem adotada historicamente foi predominantemente voltada à repressão, sendo necessário investir de forma mais orgânica em prevenção, 
https://doi.org/10.20873/uft.2359-0106.2020.v7n2.p449-461

acolhimento, redução de riscos sociais e à saúde e na formação intensa sobre o assunto (CRUZ; ALMEIDA, 2019).

Consideramos a multiplicidade de ideias e saberes, acadêmicos e nãoacadêmicos, acerca do fenômeno de uso de drogas e da política pública relativa ao assunto, a partir do entendimento de que os diálogos não são fechados em perspectivas isoladas; mas sim, devem interagir através das amplitudes de cada sujeito social, e suas possibilidades de elaboração em torno de evidências que apontem a necessidade de se encontrar as melhores soluções para cada pessoa, em consonância com o seu contexto social.

Por esse prisma, o LabSocial - Drogas tem por objetivos promover uma discussão interdisciplinar e horizontal sobre o tema das drogas, buscando a sensibilização dos sujeitos sociais para uma compreensão mais alargada sobre 0 assunto; realizar diálogos em perspectiva horizontal, com a finalidade de promover reflexões sobre a complexidade desse fenômeno na contemporaneidade, em prol do desenvolvimento de melhores estratégias para se lidar com o mesmo nos mais variados contextos sociais; e, dialogar sobre o assunto a partir das experiências e dos objetivos dos envolvidos, com foco em um novo sentido de vida. Sua elaboração ocorreu durante o primeiro semestre letivo do ano de 2019, por meio do diálogo horizontal entre os componentes do grupo extensionista que assina este relato, como uma construção coletiva, a partir de encontros para nivelamento e delimitação do conteúdo e do público alvo das primeiras ações. O projeto foi criado com previsão de atuação extensionista com distintos públicos, de maneira abrangente, sem distinções de classe social, idade e raça. Entretanto, para este primeiro momento pensamos no diálogo entre jovens (universitários e secundaristas).

O contexto escolar foi escolhido e a execução foi realizada na Escola Estadual Elizângela Glória Cardoso, localizada na cidade de Palmas-TO, uma escola de Ensino Médio em tempo integral, com cerca de 700 jovens à época da intervenção extensionista em tela. Participaram das atividades 25 secundaristas, sendo 21 representantes de turmas, mais quatro lideranças estudantis indicadas pela direção da escola em função de seus protagonismos naquele ambiente. O público foi definido por meio de diálogo com a direção em função da capilaridade dos líderes junto aos demais 
https://doi.org/10.20873/uft.2359-0106.2020.v7n2.p449-461

estudantes, e da possibilidade de atuarem como multiplicadores dentro da escola em discussões futuras relativas ao assunto.

O uso das drogas, sejam elas lícitas ou ilícitas, é realizado por todas as classes sociais e todas as faixas etárias, de modo que as políticas públicas e as ações relacionadas ao tema devem ser realizadas para e com toda a sociedade, por meio de abordagens pautadas em evidências, pelo diálogo e pela compreensão do fenômeno de uso de drogas a partir da relação das pessoas com o mundo. Entretanto, a preocupação em relação à juventude - faixa etária compreendida dos 15 aos 29 anos, segundo o Estatuto da Juventude, Lei 12.852/2013 - é válida por se tratar de um grupo etário em desenvolvimento físico, psíquico e emocional, além de compreender um período da vida marcado por distintas tensões e angústias.

Para Dayrell (2003), devemos pensar em juventudes, de forma plural, pois cada jovem possui suas individualidades e costumes conforme os contextos sociais em que vivem. Assim, com o LabSocial - Drogas, enfatizamos os jovens como seres sociais, buscando promover reflexão para o desenvolvimento da autonomia e das habilidades pessoais e sociais dos envolvidos.

A partir do exposto, no próximo tópico abordamos o processo de elaboração do projeto como um exercício dialógico entre jovens universitários como meio de preparação para as intervenções extensionistas que constituem o diálogo entre a Universidade e a sociedade.

\section{A EXTENSÃO UNIVERSITÁRIA COMO EXPERIÊNCIA DIALÓGICA}

A educação superior visa profissionalizar, iniciar à prática científica e formar a consciência político-social do estudante. Para tanto, a Universidade desenvolve de forma articulada o ensino, a pesquisa e a extensão no processo de criação do conhecimento, sua reprodução e socialização. (SEVERINO, 2017). De acordo com o estabelecido na Resolução n. 7, de 18 de dezembro de 2018, da Câmara de Educação Superior no Conselho Nacional de Educação, 


\section{https://doi.org/10.20873/uft.2359-0106.2020.v7n2.p449-461}

Art. 3ำ A Extensão na Educação Superior Brasileira é a atividade que se integra à matriz curricular e à organização da pesquisa, constituindo-se em processo interdisciplinar, político educacional, cultural, científico, tecnológico, que promove a interação transformadora entre as instituições de ensino superior e os outros setores da sociedade, por meio da produção e da aplicação do conhecimento, em articulação permanente com o ensino e a pesquisa. (BRASIL, 2018, s/p).

Assim, se através da pesquisa articula-se o ímpeto investigativo no ensino, é na extensão "[...] que o pedagógico ganha sua dimensão política, porque a formação do universitário pressupõe também uma inserção no social, despertando-o para o entendimento do papel de todo saber na instauração do social” (SEVERINO, 2017. p. 34). É através da extensão universitária que o sujeito/estudante relaciona o conhecimento científico com sua realidade social, com ela funcionando "[...] como cordão umbilical entre a Sociedade e a Universidade, impedindo que a pesquisa prevaleça sobre as outras funções, como função isolada e altaneira na sua proeminência" (SEVERINO, 2017, p. 36).

Na UFT o processo formativo relativo à extensão vem sofrendo aprimoramento constante; o que culminou nas alterações previstas pela Resolução Consepe/UFT n. 8 de 14 de março de 2018, regulamentando as ações extensionistas no âmbito da instituição. Os estudantes do grupo extensionista desenvolveram o projeto LabSocial Drogas sob orientação docente e técnica ao cursarem as disciplinas de Seminários Interdisciplinares no Curso de Direito da UFT, onde a extensão já é trabalhada de forma curricular desde o ano de 2011, estando em processo de amadurecimento de sua compreensão tanto no que se refere ao alcance das práticas extensionistas, quanto de sua importância para as atividades de ensino e pesquisa.

O fazer em curso já nos permite refletir acerca de um amplo leque de possibilidades pedagógicas para além da sala de aula que, intimamente ligadas ao processo de ensino-aprendizagem, se misturam com a vida de docentes e discentes dentro e fora da IES. As atividades relacionam projetos com disciplinas de Seminários Interdisciplinares I, II e III8 (e com as demais disciplinas do curso), desafiando a atuação

8 Disciplinas do eixo de integração que consistem na integralização da carga horária de 180 horas semestrais (12 créditos - 60h cada), mediante matrícula e realização de processo de avaliação de ensino e aprendizagem. Os estudantes têm 0 arbítrio para escolher o momento de integralização da carga 
https://doi.org/10.20873/uft.2359-0106.2020.v7n2.p449-461

coletiva a uma aprendizagem plural e interdisciplinar. Nesse contexto, o LabSocial Drogas é um espaço formativo dialógico, em que a proposta é compreender a realidade dos sujeitos e de seus contextos sociais, e refletir juntos acerca de caminhos ao entendimento da problemática das drogas na atualidade, considerando-as como qualquer substância com a capacidade de realizar mudanças nas funções comportamentais, ou até mesmo fisiológicas nos organismos vivos.

O termo "Laboratório", no sentido clássico da palavra, representa um ambiente propício para se elaborar o conhecimento pela observação e experimentação, por meio do rigor científico. A criação do LabSocial provocou-nos a necessidade de um conceito de Laboratório Social que atendesse aos objetivos do projeto; entretanto, nos esbarramos na carência de fontes acadêmicas a respeito do que seria de fato um Laboratório Social. Encontramos uma perspectiva apresentada para o setor empresarial pela Empresa Social Reos Partners (2019), que utiliza os laboratórios sociais como intervenções intensivas e experimentais e não meramente oficinas, visto que essas promovem intervenções apenas esporádicas e pontuais. Nessa proposição para o campo empresarial, o foco estaria concentrado nas causas, considerando-se que, o que maioria de nós chama de "problemas" seriam normalmente sintomas. (REOS PARTNERS, 2019).

A Empresa Social Reos Partners reúne pessoas de diferentes setores para a reflexão dos problemas e busca de soluções, de modo que "[...] o trabalho para a mudança continua no 'laboratório' da vida real - ao longo do tempo e de acordo com o contexto." (REOS PARTNERS, 2019, s/p). Trata-se de reuniões contínuas e sistemáticas para a discussão da realidade social a partir da diversidade de pessoas afetadas e/ou envolvidas no problema em questão, considerando-se também a multifatorialidade envolvida na relação com os sistemas. Neste processo, valoriza-se também a divergência e a discordância de pontos de vistas "como um antídoto ao senso comum coletivo" (REOS PARTNERS, 2019, s/p), para o desencadeamento de energia, que habilmente administrada torna-se criativa e produtiva, ou seja, construtiva.

horária das disciplinas, desde que cumpridos os pré-requisitos de Metodologia Científica e Leitura e prática de produção textual, para ingresso em Seminário Interdisciplinar I. 


\section{https://doi.org/10.20873/uft.2359-0106.2020.v7n2.p449-461}

A partir dessa visão foi pensada uma adaptação para o ambiente acadêmico, mais precisamente ao campo da extensão universitária, de modo que o conceito de Laboratório Social fosse delimitado a partir de uma construção metodológica que juntaria a perspectiva apresentada pela Reos Partners (2019) e os pressupostos da Filosofia Pop, conceito elaborado pela filósofa Marcia Tiburi (2012, 2015, 2016), favorecendo bases para a criação de novos métodos possíveis e abrindo possibilidades a estratégias inclusivas e dialógicas.

Para relacionar o passo inicial dado a partir da Filosofia para o método que estávamos a elaborar, foi necessário delimitar o que seria Filosofia Pop, no sentido de uma tentativa inversa à repetição da "História da Filosofia" como erudição vazia e o questionamento das fontes dessa esfera do conhecimento rumo aos conteúdos rejeitados do nosso tempo, de modo que julgamos o tema 'Drogas' um destes problemas de nossa cultura tratado com desprezo e/ou rejeição 9 .

A Filosofia Pop, enquanto regime de pensamento, exige uma postura experimental e criativa, a quebra da hierarquia das fontes na abordagem de conteúdos rejeitados no sentido de uma "[...] uma leitura do tempo, naquilo que ele tem de esquecido" (TIBURI, 2016, p.120), criando um campo de abstração necessário para a reflexão, onde nos apropriamos de produtos culturais como filmes, notícias, obras de arte, textos, conceitos e o senso comum. No âmbito do projeto LabSocial - Drogas a tomamos como ponto de partida para pensar o problema das drogas, tendo em vista o que o mesmo podia nos dizer sobre a nossa sociedade contemporânea, dando ferramentas para que os jovens participantes refletissem com mais profundidade sobre um tema tratado como tabu no senso comum.

Nesse sentido, o que tomamos por '“conteúdos desprezados' implica uma lista de aspectos que poderíamos classificar no campo que se estende entre o corpo, a arte e a loucura", levando em conta que "o conteúdo limita o método" fazendo com que a “[...] filosofia neste momento se apresenta como 'campo de dejetos', 'campo de rejeitos"'

${ }^{9}$ Conforme aponta Tiburi (2012, s/p), nas teses 4 e 5 de seu manifesto em 16 teses: "4 - Tendo como princípio que conteúdos rejeitados projetam luz sobre a experiência de uma época, a tarefa da Filosofia POP implica o trânsito entre afetos e representações tratadas como lixo, resto, dejeto: S'Obra; 5 Filosofia POP é a pesquisa com as obras, mas o que ela deseja mesmo é entender a vida que jaz na S'Obra." 
https://doi.org/10.20873/uft.2359-0106.2020.v7n2.p449-461

(TIBURI, 2016, p.116) no qual nos incumbimos de transitar. Aqui, necessariamente a palavra "Filosofia" tem um sentido próprio e diverso do corrente na academia e no senso comum ao anexar o termo "pop" em referência ao diálogo da filosofia com a estética a partir da Pop Art, ou seja, o confronto da filosofia com uma dada discursividade não convencional para a filosofia, que não era seu objeto 'próprio'. Esse como provocação ao modo tradicional de apresentação da filosofia como narração de sua história. Nesse prisma,

Filosofia Pop é um modo de pensar filosófico, ou seja, um método, que se faz questionando a necessidade da nobreza das fontes. Em outras palavras, se a Filosofia tradicional é feita a partir dos textos de filósofos de uma determinada tradição, a Filosofia pop é aquela que, em um sentido muito simples, se realiza a partir de outros textos, não apenas da tradição greco-latina. Ela tem relação direta com a Filosofia crítica enquanto está atenta aos conteúdos obscuros de sua época, enquanto eles são culturais. (TIBURI, 2015, p. 10, grifo nosso).

Nessa lógica, a Filosofia Pop foi o método predominante na criação de um conceito de Laboratório Social que atendesse às demandas do LabSocial - Drogas, como um espaço de diálogo horizontal e, por meio da interface entre as artes, as ciências e a "Filosofia" e até mesmo o senso comum de cada participante, ao mesmo tempo em que questiona acerca das implicações dos produtos culturais e dos contextos sociais na abordagem da temática "drogas". Assim, a partir da perspectiva interdisciplinar e transversal ${ }^{10}$, a criação desse projeto desempenhou um esforço para a abordagem de um mesmo fenômeno através de vários ângulos, produzindo percepções e ações, e a metodologia dialógica empregada pode ser utilizada em laboratórios dos mais variados temas com recorte para o social.

O elemento 'pop' como resgate do caráter investigativo, crítico, dialógico, experimental da Filosofia, foi utilizado para a apropriação de vários produtos culturais, com a finalidade de refletir sobre o tema das drogas, sob o qual paira tabus, lembrando

10 No contexto da criação do LabSocial - Drogas, consideramos, conforme Brasil (1997, p. 31), que transversalidade e interdisciplinaridade "se fundamentam na crítica de uma concepção de conhecimento que toma a realidade como um conjunto de dados estáveis, sujeitos a um ato de conhecer isento e distanciado." Com isso, consideramos o real a partir de sua complexidade e da necessidade de compreensão da "teia de relações entre os seus diferentes e contraditórios aspectos". (BRASIL, 1997, p. 31). 
https://doi.org/10.20873/uft.2359-0106.2020.v7n2.p449-461

que todos os ditos "filósofos" não fizeram nada mais que refletir os problemas de seu próprio tempo e em seu próprio espaço, ou seja, em seus contextos. Dialogar abertamente a partir de produtos culturais ${ }^{11}$, científicos e da fala e escuta da experiencia individual dos participantes, na tentativa de conscientizar e desmistificar o tabu das drogas é o que objetivamos neste projeto. A seguir, demonstramos como ocorreram as primeiras intervenções in loco, pautadas pelo diálogo entre a equipe executora e o público-alvo.

\section{O LABSOCIAL - DROGAS: DIÁLOGO HORIZONTAL EM QUATRO MOMENTOS FORMATIVOS}

Após intensa preparação da equipe, as intervenções foram realizadas em quatro momentos formativos, sendo dois realizados no mês de junho de 2019, com a carga horária de $1 \mathrm{~h} 40$ cada, e os demais nos meses de setembro e outubro do mesmo ano, com $1 \mathrm{~h}$ de duração cada ${ }^{12}$. Nos quatro módulos, a exposição foi realizada no modelo tradicional, mas as discussões foram feitas em uma colcha de retalhos colorida estendida ao chão, ornamentada com algumas almofadas também coloridas, de modo que todos se acomodassem à vontade, sentados ou mesmo deitados, em ambiente acolhedor, sem interferências dos profissionais da escola, ou seja, somente com a presença dos acadêmicos, dos secundaristas e da professora orientadora. Na Imagem 1, abaixo, aparecem os estudantes universitários do projeto em exposição de conteúdo no primeiro encontro, e podemos observar os dois cenários, um para o momento inicial de exposição, seguida das discussões horizontais que eram realizadas no ambiente reservado ao fundo.

\footnotetext{
11 Utilizamos políticas públicas, vídeos curtos, trechos de matérias jornalísticas, legislações e animações artísticas e metafóricas para instigar à reflexão e promover os diálogos.

12 A redução na carga horária, nos terceiro e quarto encontros, ocorreu em função das intensas atividades da escola no final do ano, e afetou o desenvolvimento do projeto, levando a equipe a atuar de maneira dinâmica, dando mais ênfase na troca de informações e nos debates e menos nas exposições.
} 


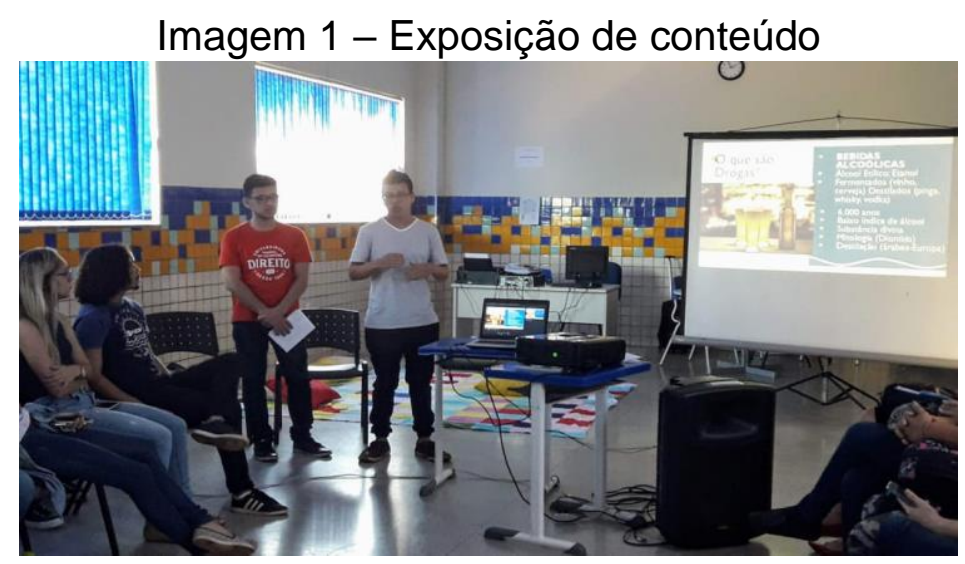

O mesmo cenário foi utilizado em todas as intervenções. No primeiro semestre de 2019 foram realizados os encontros temáticos "O que são drogas?" e "Uso de drogas e responsabilidade" e no segundo semestre os encontro sobre "Como lidar?" e "Políticas Públicas e Redes de Atenção", voltados para o papel estatal/institucional de atenção, prevenção e cuidado, e também sobre as atualizações na política pública, por meio do Decreto $n^{\circ}$ 9.761/2019, que aprovou a nova Política Nacional sobre Drogas, bem como da Lei $n^{\circ}$ 13.840/2019, que alterou a Lei n. 11.343/2006 (Lei de drogas). O último encontro teve foco em "Protagonismo e desenvolvimento de habilidades sociais", quando trabalhamos, dentre outras coisas, a participação dos jovens como atores, sujeitos ativos de suas histórias.

Durante as exposições dos conteúdos de nivelamento/preparação para os debates, observamos o interesse pelo tema por meio da ampla participação dos jovens, o que interpretamos como elemento de um protagonismo incentivado pela Escola em função de seu projeto pedagógico, vez que a mesma integra o projeto Escola Jovem em Ação ${ }^{13}$ que incentiva o protagonismo e o projeto de vida. Os momentos de reflexão e diálogo foram orientados por questões postas como um direcionamento teóriconormativo ao debate. Os participantes puderam expor suas percepções acerca do assunto e partilhar, como sujeitos ativos motivados durante todas as atividades para que o diálogo ocorresse de fato de modo horizontal, possibilitando a troca tanto de experiências e quanto de afetos.

13 Programa de Fomento à Implementação de Escolas de Ensino Médio em Tempo Integral, por iniciativa do Governo Federal em parceria com os estados. 
https://doi.org/10.20873/uft.2359-0106.2020.v7n2.p449-461

Nessa experiência, com a aplicação da filosofia como amplificadora do debate, os participantes apontaram para diferentes problemáticas relacionadas tanto a substâncias lícitas e ilícitas, quanto ao uso de aparelhos eletrônicos que geram também vícios de correção estética através das redes sociais e publicidade, e de cognição pelo contato exacerbado com suas telas, o que foi possível através do conceito de "esteticomania"14 discutido por Tiburi e Dias (2013) como material interdisciplinar, ficando notória, por exemplo, a expansão do conceito de vício.

\section{CONSIDERAÇÕES FINAIS}

A criação coletiva, bem como a execução inicial do laboratório de ideias no contexto da extensão universitária realizada por meio do LabSocial-Drogas foi fruto de diálogo e troca de saberes em perspectiva horizontal. Trata-se de um trabalho que apenas é possível em decorrência do diálogo estabelecido pelo grupo no sentido de nivelamento dos conteúdos e alinhamento dos interesses de cada membro, sobretudo a partir do entendimento do conceito de Filosofia Pop.

Foi fundamental a compreensão dos conceitos de interdisciplinaridade e transversalidade, como princípios norteadores das disciplinas de Seminários Interdisciplinares do Curso de Direito da UFT, promovendo olhares abrangentes pautados pela diversidade de saberes, e demandando dos acadêmicos a realização de pesquisas para a fundamentação necessária, vivenciando, assim, o tripé ensinopesquisa-extensão.

O amadurecimento dos membros do grupo extensionista, cuja evidência é por si só a capacidade de execução exitosa das atividades propostas - com a consequentemente melhor qualificação do projeto identificada por meio de avaliação do próprio grupo - se deu a partir do momento em que houve a compreensão de que se deveria partir do diálogo e cooperação entre os estudantes e a orientadora, e da equipe com o público alvo da ação.

14 A partir desse conceito foi possível abordar também a relação sujeito-objeto. Por exemplo, na discussão sobre os estágios de abstinência, fissura e crise de personalidade os estudantes conseguiram realizar nexo com outras experiencias 'viciadas' contemporâneas como o uso de videogames, redes sociais, fast-food, padrões de imagem etc., percebendo possibilidades de prejuízos na relação com objetos ou padrões. 
https://doi.org/10.20873/uft.2359-0106.2020.v7n2.p449-461

No processo de intervenção, constatamos, ao contrário do que havíamos pressuposto, que a maioria dos jovens secundaristas participantes já possuíam entendimento preliminar sobre a temática e estavam atualizados em relação às mudanças recentes na política pública, colaborando efetivamente com a realização da extensão, tornando a experiência extensionista do laboratório de ideias ainda mais enriquecedora para todos.

Por meio da abordagem do tema "drogas", consideramos efetiva a metodologia do laboratório de ideias elaborada a partir dos pressupostos da Filosofia Pop, em consideração aos temas rejeitados do nosso tempo, em função seja de preconceito, seja de ignorância ou receio, e salientamos que para problemas complexos não existem soluções fáceis, rígidas e/ou planejadas no papel.

No caso específico da atenção ao uso de drogas por escolares, acreditamos que as escolas ainda são espaços especiais para o desenvolvimento de estratégias de prevenção ao uso indevido, sobretudo se enfatizarem sempre a reflexão, o diálogo, com a premissa de desenvolvimento da autonomia e das habilidades pessoais, para a vida e para a inserção produtiva e social.

\section{REFERÊNCIAS}

ALMEIDA, Cristiane Roque de. O protagonismo do CRR/UFT/Centro-Sul e o diálogo intersetorial na política sobre drogas no Tocantins. In: ALMEIDA, Cristiane Roque de; CARIAGA, Helena Maria; JOVELI, Sílvia Regina da Silva Costa (Org.). O CRR no Tocantins: articulando saberes para o cuidado em uso abusivo de álcool e outras drogas. Curitiba: CRV, 2017. p. 23-35.

BRASIL. Decreto ํㅜ 9.761, de 11 de abril de 2019. Política Nacional sobre Drogas. Disponível em: <http://www.planalto.gov.br/ccivil03/ato2019-2022/2019/decreto/D9761.htm>. Acesso em: 12 abr. 2019.

Lei no 12.852, de 5 de agosto de 2013. Estatuto da Juventude. Institui o Estatuto da Juventude e dispõe sobre os direitos dos jovens, os princípios e diretrizes das políticas públicas de juventude e o Sistema Nacional de Juventude - SINAJUVE. Disponível em: <http://www.planalto.gov.br/ccivil_03/_ato2011-2014/2013/lei/l12852.htm>. Acesso em: 12 abr. 2019.

Ministério da Educação. Conselho Nacional de Educação. Câmara de Educação Superior. Resolução no 7, de 18 de dezembro de 2018. Disponível em: 
https://doi.org/10.20873/uft.2359-0106.2020.v7n2.p449-461

$<$ http://portal.mec.gov.br/index.php?option=comdocman\&view=download\&alias=104251rces007-18\&category_slug=dezembro-2018-pdf\&ltemid=30192>. Acesso em: 30 de out. 2019.

. Secretaria da Educação Fundamental. Parâmetros Curriculares Nacionais: meio ambiente. Brasília: MEC/SEF, 1997.

CRUZ, Wanderlei Fernandes da; ALMEIDA, Cristiane Roque. A questão social das drogas no Brasil: a predominância histórica da repressão. Vertentes do Direito, Palmas-TO, vol. 6, $n^{\circ} 1$, 2019. Disponível em: <https://sistemas.uft.edu.br/periodicos/index.php/direito/article/view/6114>. Acesso em: nov. 2019.

DAYRELL, Juarez. O jovem como sujeito social. Revista Brasil Educação, n. 24, p. 40-52, 2003. Disponível em: <http://www.scielo.br/pdf/rbedu/n24/n24a04.pdf>. Acesso em: 09 out. 2019.

REOS PARTNERS [Empresa Social]. Método: Laboratórios Sociais - Plataformas para a criação de soluções que funcionam no mundo real. Revista Reos Partners. Disponível em: <https://reospartners.com/pt-br/tools/laboratorios-sociais/>. Acesso em: 17 set. 2019.

SEVERINO, Antônio Joaquim. Metodologia do trabalho científico. Cortez editora, 2017.

TIBURI, Márcia Angelita. A filosofia e seus conteúdos rejeitados: Filosofia pop em questão. Revista Sinais Sociais. Rio de Janeiro, v. 10, n. 30, p. 96-164, jan./abr., 2016.

- A Filosofia Pop. Revista SescTV. São Paulo, 2015. Disponível em: https://www.sescsp.org.br/online/artigo/9496_A+FILOSOFIA+POP. Acesso em: 20 nov. 2019.

. Filosofia Pop: Manifesto em 16 teses. Revista Cult [online] 21, mar. 2012. Disponível em: https https://revistacult.uol.com.br/home/filosofia-pop-manifesto-em-16teses/\#: :text=2\%20?\%20Filosofia\%20POP\%20\%E9\%20um,burocracia\%20enquanto\%20suste nta\%20a\%20repeti\%E7\%E3o. Acesso em: 02 set. 2019.

TIBURI, Márcia Angelita. Filosofia prática: ética, vida cotidiana, vida virtual. Rio de Janeiro: Record, 2014.

TIBURI, Márcia Angelita; DIAS, A. Sociedade fissurada: para pensar as drogas e a banalidade do vício. Rio de Janeiro: José Olympio, 2013.

UFT. Conselho de Ensino, Pesquisa e Extensão - CONSEPE. Resolução no 8, de 14 de março de 2018. Dispõe sobre o regulamento das ações de extensão da Universidade Federal do Tocantins e dá outras providências. Disponível em: https://docs.uft.edu.br/share/proxy/alfresconoauth/api/internal/shared/node/oVqwXL41TO64dmrhpj1fBg/content/08-2018\%20\%20Regulamento\%20A\%C3\%A7\%C3\%B5es\%20de\%20Extens\%C3\%A30\%20da\%20UFT\%20. $\begin{array}{lllll}\text { pdf. } & \text { Acesso } & \text { em: } & & \end{array}$ 